\title{
BIM AND AGENT-BASED MODEL INTEGRATION FOR CONSTRUCTION MANAGEMENT OPTIMIZATION
}

\author{
Francesco Livio Rossini ${ }^{1}$, Gabriele Novembri ${ }^{2}$, and Antonio Fioravanti ${ }^{3}$
}

\begin{abstract}
The current necessity of manage complexity in the field of building process management push to provide process' figures of construction methodologies and tools capable to support them in a proficient way. With the scope to define in advance the places occupied by workers to accomplish a task, is defined a methodology and related tools to integrate Building Information Modeling (BIM) with an Agent-Based simulation of workers activities. The goal is to know at early project phases where it is possible to work in a more effective and safer way, how it is possible to be more efficient placing in the same working space different working phases and when it is possible to allow the continuity of building operations. The outcome of the system is predicting how much resources are involved in a project, identifying and minimizing wasted time.
\end{abstract}

Keywords: BIM, Project and Construction Management, Lean construction, AgentBased Simulation.

\section{INTRODUCTION}

The industry of $\mathrm{A} / \mathrm{E} / \mathrm{C}$ is characterised by a huge complexity that has multifaceted aspects, due to the variety of new materials, design solutions and the need to respect pressing timetables and narrow budgets. This ever-growing complexity, furthermore, is less manageable when, i.e. during refurbishments, in the same building construction workers and building users are present, with the sake to ensure the continuity of building use.

Moreover, is difficult to manage users and workers by means of the usual Building Codes or 'rules of thumb', expressed in handbooks - even if digital - as we were in the XIX century. Nowadays, with the introduction and the progressive spreading of the engineering approach, it is time to deal with new and old complexities.

During the last decades, the development of Information and Communication Technologies (ICT) allowed the simplification of building process management thanks to the automation of reasoning tasks, for instance 'clash detections' and 'rule checking' (Solihin and Eastman, 2015).

Evidently, these improvements provided designers of useful tools able to predict the effects of their choices and, consequently, to avoid as possible mistakes and misunderstandings, which are important complementary causes of construction delay, unexpected costs and possible injuries during the working-phases.

PhD Candidate, in Engineering-based Architecture and Urban Planning - Sapienza University of Rome, Rome, ITA, francesco.rossini@uniroma1.it

2 Aggregate Professor, Dept. of Civil, Constructional and Environmental Engineering, Sapienza University of Rome, Rome, ITA, gabriele.novembri@uniroma1.it

3 Aggregate Professor, Dept. of Civil, Constructional and Environmental Engineering, Sapienza University of Rome, Rome, ITA, antonio.fioravanti@uniroma1.it 
The paper's aim is to describe a use of the Artificial Intelligence (AI) technique of Agents-based simulation with the sake to support choices in construction management, in order to prevent risks like the overlapping of activities, wasted time, under-used spaces and resources and, consequently, improve productivity of construction sites allowing, where required, the continuity of building use.

Nowadays Information Modeling methodologies shown great potential in $\mathrm{A} / \mathrm{E} / \mathrm{C}$ field, contributing designers in the management of the complexity of large quantity of information, allowing also the automatic identification of conflicts, mainly geometrical (Singh et al., 2011). At the same time, they have not shown clear capabilities in associating building entities and their assigned resources with their construction methods, required materials, execution time and generated interferences.

The support that these tools provide in architectural design, and the need to move toward the simplification of the overall project organization model construction from the initial stages of design, could suggest appropriate choices of production techniques, optimizing required construction time and mitigating risks.

However, Building Information Modeling (BIM) and integration of project management tool is difficult to realize by means of scheduling traditional techniques like Program Evaluation and Review Technique (PERT) and the quite-similar Critical Path Method (CPM) techniques; it requires, conversely, an explicit representation of management and assessment to:

- Working team behaviours on the construction site;

- Space required for the execution of the work to be carried out;

- Number and type of the resources involved.

Thus, techniques based on Location-Based Structure (LBS) are more suitable to develop such a different approach (Kenley and Seppanen, 2009).

Location is very important in AEC as it is linked to main characteristic of a building whether used space for construction-related activities. In this paper is described how automatically define a single 'location' called $<$ Room $>$ in a BIM environment via a specific application. Term 'location' means the space required by a working-team to reach its goal.

\section{STATE OF THE ART}

\subsection{BIM (Building Information Modeling) and simulation in construction management field}

There are different definitions of BIM, coined by the first generation involved in this field (Eastman et al., 2011) but, for the purpose of this paper, we consider the 'Building SMART' alliance definition (2012), that describes BIM as a 'digital representation of physical and functional characteristics of a facility'. As such, it serves as a shared knowledge resource for information about a facility forming a reliable basis for decisions during its lifecycle from inception onward.

A basic premise of BIM is collaboration of different stakeholders at different lifecycle phases of a facility to insert, extract, update or modify information in the BIM to support and reflect the roles of actors involved.

This defines how this methodology acquire essential information to manage a construction site. In fact, interventions on existing buildings have as first requirement knowing the starting-point situation. 
Thus, a BIM model can contain appropriate information for construction like the property of materials used in construction, potential risks or details that can improve the level of the working-area conditions awareness and, consequently, safety conditions.

However, uncertainty in existing building data cannot be avoided unless a complete field inspection is undertaken, and there is still a risk of human error. Three approaches may be used to manage the uncertainty of data in a BIM model: (1) verification, (2) acceptance or (3) avoidance.

These are determined individually - for example if a subset of equipment was fieldlocated and 50\% were found exactly as indicated on the available drawings, they would be $50 \%$ certain - and only elements with a minimum certainty are modelled. Third, data below this certainty level (which may be $99 \%+$ for some organizations) is omitted from the model.

This final option is the least expensive but may severely limit the model functionality (McArthur, 2015).

Finally, BIM is a promising digital methodology to collect and represent information, but lacks of technique, methods and related tools capable to predict the feasibility, time and costs related to a construction process.

In the other hand, this promising methodology show lacks toward the construction management sector: as a matter of fact, the most widespread software for construction specialists (i.e. Navisworks, Trimble Vico, Synchro etc.) are very useful to set the timing of activities, to verify clashes in a BIM model or quantify - in an appropriate way - the related costs. However, a lack of these tools is in the domain of the prediction of choices result: indeed, the current software work on the base of data provided by the implicit knowledge of designer, and rely only on the expertise of specialists involved.

To overtake these limits, several researches introduced techniques of artificial intelligence on building construction field, like multi-agents. These technique indeed allow to link process management with stochastic approach (Taillandier et al, 2015), using discrete evaluation by means of simulation of each risk involved in a project. Furthermore, was also developed methodologies to plan automatically the construction site with genetic algorithm for optimization of the safer paths in the site, based on BIM models (S. S. Kumar and J. C. P. Cheng, 2015). In addition, was explored other fields of artificial intelligence like ontology (R.J. Scherer and S. E. Schapke, 2011) and semantic web technology (L. Y. Ding et al., 2016). Eventually, to increase the precision of simulation results, other studies focused on the hybrid simulation approach, proposed to facilitate integration of safety management consideration into construction activity simulation by means of System Dynamics (SD), Discrete Event Simulation (DES) and Agent Based Simulation (ABS). This system, evidently, seems to be the best approach to solve the problem of predicting the more appropriate choices to take into account during construction (Goh Y., M., and Askar Ali, M., A., 2015) but, considering the overlapping of heavy dimension of computations needed by these methods, is viable only on limited cases.

To exceed this gap, in this research is proposed to link Agent-Based simulation to BIM environment, via an application that, in the BIM environment, specify the space needed to complete an activity. The aim is to analyse the risks related to specific phases in their specific context, predicting how many time an activity concretely requires.

\subsection{ABM (Agent-Based Modeling) in architectural construction sites}

Building is a complex activity. Nevertheless, this complexity is the sum of simple issues, which are often solved by small worker-teams or, in many cases, by single worker. For this reason, agent-based modeling is very near to the real phenomenon, and can model 
accurately the interaction among them and between agents and the context given, in this case, by the related BIM model.

Furthermore, in ABM the ontological correspondence between the computer agents in the model and in the real world actors makes it easy and evident to represent actors and the environment and their relationship (Gilbert, 2008), working also on different levels of abstraction, starting from the lower 'reactive' level, to an higher 'proactive' level (Novembri et al., 2015).

The project construction management is a realm very near to the $\mathrm{ABM}$ method capabilities, because this field involves cross-disciplinary problems like social and human aspects, and both spatial and temporal interactions among different participating teams (Liang, 2012). On the other hand, current BIM and Construction Management tools provide embedded agents-inference engine: these tools are able to represent the working phase duration (4D) or costs (5D) only if the designer sets data following his implicit knowledge. Indeed, the method here described allows the solution of a part of the general problem. This application, in effect, provide managers to know how much space is needed to workers to reach their goals by automatic reasoning given by agents' inference.

\section{THE IMPACT OF BIM AND ABM IN A LEAN CONSTRUCTION PROCESS: APPLICATIVE METHODOLOGY}

\subsection{Modelling agents to interact with building construction issues: brief program framework}

To describe agent-based program operation and to give an actual example of it, a small Windows Presentation Foundation (WPF) in C\# language with more updated pattern of parallelization with the aim of enhancing concurrency among agents. In this prototype the thread elimination is only a visual omission, because the thread continues computing operation in background.

More precisely, when a dimensional input given in a BIM environment is defined, the interaction among several agents begin, characterized by different rules, behavior and, substantially, goals (Castelfranchi and Falcone, 1998).

Thus, the aim is the optimization of spaces where the working-phases are located during the global operation of the building, avoiding inhibitions of its social function.

Agents are located in a workspace that have specific requirement and constraints: when all agents find a satisfying condition, the solution is given.

Specifically, every agent geometrically modifies this working-space and, when the modifications required by agents are not in collision among them, the final boundary is defined. During simulations, we demonstrated (fig. 1) that areas defined by simulation tool is considerably smaller than areas forecasted by the construction site planner.

Since these processes happen in parallel mode, the conclusion of a method stops other agents modifying the state of starting instance, until the next iterative cycle starts.

Every execution, therefore, produces similar but different results; it is not possible, effectively, to control the thread priority and execution speed because memory access is exclusively random: we conceptually can compare this selection process to the spermatozoa trip toward the ovum.

Thus, the agent that modifies the possible space occupied by the workers is the first that ends the entire optimization that satisfies all other agents' requirements. Note that this is not the only possible solution as it depends on agents' initial configuration. 


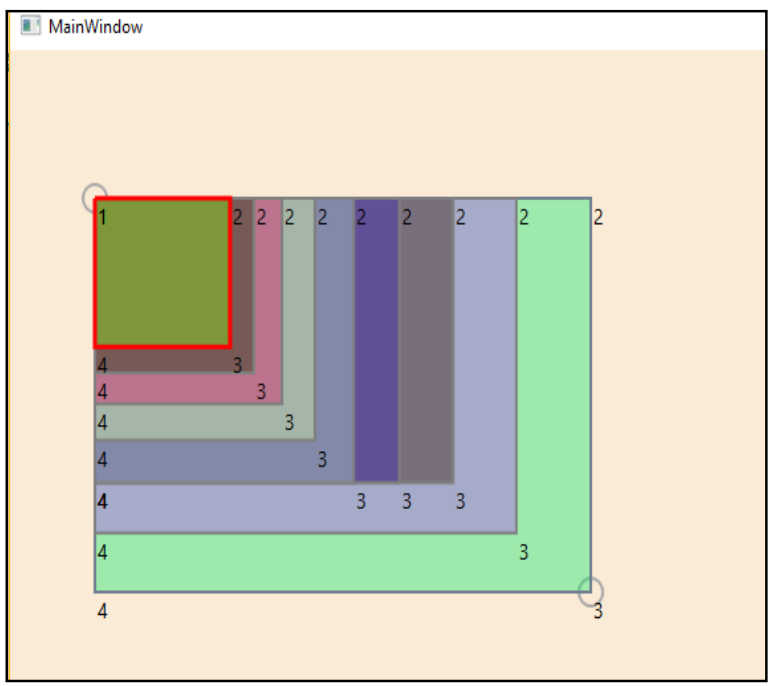

Fig. 1: Identification of an effective-working area.For an important but simple activity in the building construction field e.g. painting, we have to model several agents such as scaffolding, painters, suppliers etc. After the interaction among these intelligent entities, starting from a forecasted larger area (green), we could work in the red-bounded area in a more efficient way, allowing the use of other spaces for different activities.

As a matter of fact, an agent intervening early in the first cycle, will not necessary arrive first in the second one, as the whole cycle is random; this randomness is addressed exclusively to the prior interest to solve the problem in the most effective way, without privileging any agent.

\subsection{Modelling agents to interact with building construction issues: the first-programming phase}




For the sake of allowing a coherent graphic representation of the algorithm, the application was encapsulated in a traditional Windows ${ }^{\mathrm{TM}}$ visualization. The "base-class" is the one that describes the space vertex, or rather the "class descriptive element", allows the method to calculate the Euclidean parameters.

The "Room-constructor class", conversely, has the task to foresee the other two missing vertices necessary to represent the process (the other two vertices of the rectangle are assigned in the previous method). The $<$ Draw $>$ method, allows to design the instance in the Canvas previously defined. $<$ SetAsLast() $>$ high-lights the instance border, while $<$ SetAsBase() $>$ re-freshes the current state. The $<$ Area $>$ and $<$ Form-Factor $>$ properties define the surface dimensions and the related form-factor, set up as an important parameter to give working area reliable dimensions. To finish the first phase, we have to set up the WPF control, in which several application will be visualized. The proposed framework shows the principal graphical interface of the application. The pink surface, the Canvas, is the area where the $<$ Room $>$ is located.

\subsection{Agent execution logic}

To describe the base-structure of an agent we defined an interface that, when implemented, allows to agents to define a name, a block-function and a worker-function.

In our case, we have not implemented the block-functions, and the worker function requires access in a Room (the working-area) and the output of a new Room.

Finally, the program produce an object and requires the restitution of a new instance of the same object type. For these agents, the implementation required is <nullable> type. The <null> type, in effect, will be used in agreement of current norms to warn the agent about a completed work, or rather in a compatible state. In this way, we optimize the program interface.

\subsection{Agents management and parallelization}

To manage the parallelization process, then the sending and reception of data, we used Task Parallel Library (TPL) dataflow, which extends the namespace. <System.Thread> with several functions, turned toward data-oriented programming: a de-tailed documentation about this topic is provided by the Microsoft web-library, while the whole package is available on Nuget, because it is not included in the .NET framework (Microsoft, 2017).

The Scheduler class manage the access to four public functions that can be used by the User Interface (UI) with the aim to receive notices about the agents' state. $<$ SyncronizedAgent> will memorize information about agents, which has the synchronization priority because entered the process firstly.

$<$ AgentLastReturnedStatus $>$ contains information about the output of single agents, $<$ WorkingRoom $>$ is the currently synchronized $<$ Room $>$.

$<$ AgentsDictionary $>$ contains the $<$ TransformBlock $>$ obtained by $<$ Reflection $>$ process. The definition of auxiliary class is shown at the top of the next page.

To allow an effective operation of the agents' systems, initialization function is required and, essentially, upload the starting room - in this case the pre-defined working area - and, through the reflection mode, produces all the agents defined.

The agent broadcast has to run in a synchronous way, and includes a sort of logical reverification of results, fundamental in this experiment. <PostAndReceive $>$ is the keyfunction: its task is data checking. 


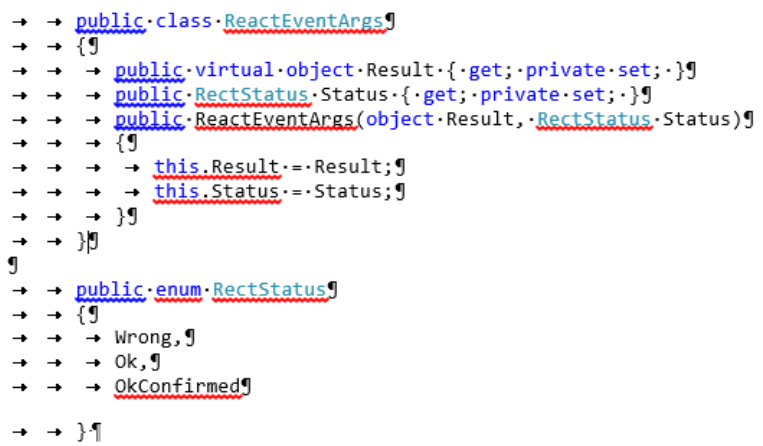

Finally, the enrolment of the WPF events is as follows: the graphic interface file is to completed with the $<$ CoreBehind $>$ capable to connect itself with the agent-based system, in addition to the definition of areas. The code task is simply to enrol the several statistic events involved in the $<$ Scheduler $>$ and provide a graphical output to be visualized in the stock panel.

\subsection{Linking ABM application and BIM}

The application developed is conceived to link the geometrical result of the iteration among intelligent agents with the "BIM-world" via the API (Advanced Programming Interface).

The dataset provided by the BIM, in this case represented by the in-stances "surface", define the agents' interaction: they react to events generated every time the surface analyzed is modified. In summary, instances are classified through their <Unique_ID $>$ and their geometrical data are imported into the Canvas (fig. 1); Here, the program identifies geometrical values and starts its computation, until the optimized working surface is obtained.

Furthermore, when an object is modified, the system updates data in order to avoid inconsistency within the BIM model. However, the interaction mode varies as a function of the type of interaction. Any request made via the BIM interface is immediately forwarded to the combined ABM application, and then the BIM awaits the completion of the task: in this case, a synchronous mode of interaction is established. Otherwise, when the ABM application needs to interact with the BIM world, a request will be show in the alert palette, waiting for the project manager validation.

\section{CONCLUSIONS}

The research started investigating the lacks of current construction management process and tools. The result is the identification of the wasted working areas and the lack of tools to predict the occupancy of area in construction site. After that, a leaner way to allocate resources in the construction site is individuated in the use of LBM (LocationBased Management).

Furthermore, a key-concept to optimization is collaboration, and the BIM methodology helps process actor in sharing information about material and drawings. Therefore, to increase the effectivity of process using reliable data, an Agent-Based simulation was linked to the BIM model, that represents the topology of these agents

Finally, the optimized area is defined by means of an Agent-Based Simulation, defining the area that a working-crew effectively need to accomplish the assigned task. The next step will be the lean management of these areas, with the scope to warrant the higher rate possible of occupancy in order to maximize the contractor's productivity. 


\section{REFERENCES}

Building Smart, international home of BIM <http://www.buildingsmart.org/> last access 13/04/2016.

Castelfranchi, C., Falcone, R., 1998, Toward a theory of delegation for Agents-Based systems, Robotics and Autonomous systems, 24 (24), pp. 141-157.

Gilbert, N., 2008, Agent-Based Models. Sage Publications, Los Angeles, p. 14.

Ding, L., Y., Zhong, B., T., Wu, S., Luo, H., B., Construction risk knowledge management in BIM using ontology and semantic web technology in Safety Science, 87 (2016) pp. 202-213.

Eastman, C. Teicholz, P., Sacks, R., \& Liston, K. (2011). BIM handbook: a guide to building information modelling for owners, managers, designers, engineers, and contractors. Wiley.

Goh, Y., M., Askar Ali, M. J., A hybrid simulation approach for integrating safety behaviour into construction planning: An earthmoving case study in Accident Analysis and prevention 93 (2016), pp 310-318.

Kenley, R., Seppänen, O., 2009, Location-based management of construction projects: part of a new typology for project scheduling methodologies in Proceedings of the 2009 Simulation Conference, Eds. Rossetti M., D., Hill, R., R., Johansson, A., Dunkin A. and Ingalls, R.G. Austin, TX, USA, December 13-16, pp 2563-2570.

Kumar, S., S., Cheng., J., C., P., A BIM-based automated site layout planning framework for congested construction sites in Automation in Construction, 59 (2015) pp. 24-37.

Liang, C., 2012, Agent-based modelling in urban and architectural research: A brief literature review. Frontiers of architectural Research vol. 1 (2012) pp. 166-177.

McArthur, J.J., 2015, A building information management (BIM) framework and supporting case study for existing building operations, maintenance and sustainability, in Procedia Engineering 118 (2015), pp. 1104-1111.

Novembri, A., Fioravanti, A., Rossini, F.L., 2015, Geometria qualitativa nel BIM-world: Generazione della Location Breakdown Structure (LBS) per un processo di costruzione sostenibile, in Environmental sustainability, circular economy and building production. Maggioli Editore, pp. 502-521.

Scherer, R.J., Schapke, S. E., a distributed multi-model-based Management Information System for simulation and decision-making on construction projects, in Advanced Engineering Informatics, 25 (2011) pp. 582-599.

Singh, V., Ning, G., Xiangyu, W., 2011, A theoretical framework of a BIM-based multidisciplinary collaboration platform in Automation in construction 20 (2011) pp. 134144.

Solihin, W., Eastman, C., 2015, Classification of rules for automated BIM rule checking development, in Automation in construction, Vol. 53 (2015), pp. 69-82.

Taillandier, F., Taillandier, P., Tepeli, E., Breysse, D., Mehdizadeh, R., Khartabil, f., a multiagent model to manage risks in construction project (SMACC) in Automation in Construction, 58 (2015), pp. 1-18.

Websites:

Laiserin J. in Laiserin Letter http://www.laiserin.com/ last access 15/02/2017.

Microsoft Developer Network at <https://msdn.microsoft.com/enus/library/gg145045(v=vs.110).aspx>, last access 06/05/2017. 